\title{
Destabilizing RET in targeted treatment of thyroid cancers
}

\author{
M L Gild' ${ }^{1}$ M Bullock ${ }^{1}$, C K Pon 1, B G Robinson ${ }^{1,2}$ and R J Clifton-Bligh ${ }^{1,2}$ \\ ${ }^{1}$ Cancer Genetics Laboratory, Kolling Institute of Medical Research, Sydney, New South Wales, Australia \\ ${ }^{2}$ Department of Endocrinology, Royal North Shore Hospital, The University of Sydney, Sydney, \\ New South Wales 2065, Australia
}

\author{
Correspondence \\ should be addressed \\ to R J Clifton-Bligh \\ Email \\ jclifton@med.usyd.edu.au
}

\begin{abstract}
Metastatic differentiated thyroid cancers (DTC) are resistant to traditional chemotherapy. Kinase inhibitors have shown promise in patients with progressive DTC, but dose-limiting toxicity is commonplace. HSP90 regulates protein degradation of several growth-mediating kinases such as RET, and we hypothesized that HSP90 inhibitor (AUY922) could inhibit RETmediated medullary thyroid cancer (MTC) as well as papillary thyroid cancer (PTC) cell growth and also radioactive iodine uptake by PTC cells. Studies utilized MTC cell lines TT (C634W) and MZ-CRC-1 (M918T) and the PTC cell line TPC-1 (RET/PTC1). Cell viability was assessed with MTS assays and apoptosis by flow cytometry. Signaling target expression was determined by western blot and radioiodine uptake measured with a gamma counter. Prolonged treatment of both MTC cell lines with AUY922 simultaneously inhibited both MAPK and mTOR pathways and significantly induced apoptosis ( 58.7 and $78.7 \%$ reduction in MZ-CRC-1 and TT live cells respectively, following $1 \mu \mathrm{M}$ AUY922; $P<0.02$ ). Similarly in the PTC cell line, growth and signaling targets were inhibited, and also a 2.84-fold increase in radioiodine uptake was observed following AUY922 administration $(P=0.015)$. AUY922 demonstrates in vitro activity against MTC and PTC cell lines. We observed a potent dosedependent increase in apoptosis in MTC cell lines following drug administration confirming its anti-tumorigenic effects. Western blots confirm inhibition of pro-survival proteins including AKT suggesting this as the mechanism of cell death. In a functional study, we observed an increase in radioiodine uptake in the PTC cell line following AUY922 treatment. We believe HSP9O inhibition could be a viable alternative for treatment of RET-driven chemo-resistant thyroid cancers.
\end{abstract}

Key Words
- thyroid cancer
- HSP90
- AUY922
- RET
- MAPK
- MTOR

Endocrine Connections (2016) 5, 10-19

\section{Introduction}

Members of the heat shock protein (HSP) family work as molecular chaperones, ensuring homeostasis and aiding in folding and trafficking of client proteins. HSP90 has been shown to mediate the folding of client proteins including signaling kinases. HSPs have become known as central regulators, whose actions are to control the activity of pathways such as cell proliferation and death, while preventing the aggregation of non-native proteins (1).
HSP90 is overexpressed in cancer cells and HSP90 ATPase activity is approximately 100 times higher in malignant cells when compared to their non-neoplastic counterparts (2). Indeed, cancer cells appear to be more sensitive to inhibition of this chaperone's activity, making it a more specific targeted therapy (3). HSP90 exists as three separate highly conserved domains; an N-terminal ATPase binding domain, a middle domain, and a C-terminal dimerization 
domain. ATP binding triggers the closure of the ATP pocket lid and brings the N-termini close to each other, resulting in the formation of a compacted, ring-shaped HSP90 dimer (4). These conformational alterations lead to a 'closed' state to 'clamp' client proteins inside. The ATPase activity of HSP90 itself drives the chaperone cycle and it is this mechanism that is exploited when targeting its inhibition (5).

HSP90 client proteins include many kinases involved in apoptosis and signaling. These include AKT (and its phosphorylated form), p53, Raf-1, Bcr-abl, and BRAF; many of these are well known for the role they play in carcinogenesis (6). Importantly, RET was also recently classified as a direct client protein of HSP90 (7). Mutant cells may even utilize HSP90 to compensate for their structural instability and it has been proposed that HSP90 is essential to the sustenance of these molecules, without which following mutation they would be hastily degraded $(5,6)$.

Geldanamycin, the first HSP90 inhibitor entered clinical trials in 1999 and had shown promise in phase II trials in a number of cancers, including breast, melanoma, and multiple myeloma, summarized in (1). It has pertinent pharmacological limitations including low water solubility, instability in solution, and low oral bioavailability (1). As well as formulation difficulties, there are significant clinical toxicity issues when using its derivative 17-AAG as a primary therapy. These include hepatotoxicity and polymorphic metabolism (8). Hence, newer compounds with similar inhibitory activity have been developed. NVPAUY922 is an isoxazole based compound that acts as a competitive inhibitor of ATP. Its administration renders HSP90 inefficient thereby destabilizing its client proteins. It has been used in preclinical studies of many recalcitrant cancers including prostate (9), non small cell lung cancer (10), and osteosarcoma (11).

With regard to thyroid cancer, early studies have yielded data that supports the potential clinical utility of targeting HSP90 to treat this disease. 17-AAG has showed an inhibitory growth effect in thyroid cancer cell lines, but no apoptosis was observed (12). The drug BTIMNP_D004 acts through HSP90 destabilization and showed anticancer activity in thyroid cancer cell lines in vitro (13). Furthermore, treatment with 17-AAG reduced papillary thyroid cancer 1 (PTC1) expression levels and increased radioiodine accumulation in PCCL3 thyroid cells where PTC1 was induced by doxycycline (14). This was determined to be independent of the sodium iodide symporter (NIS) and likely resulted from an effect of decreased iodide efflux through a PKA-mediated mechanism. While significant, this study was performed on non-cancer thyroid cell lines and requires further certification in cancer cells. Elisei et al. (15) have also shown that destabilizing HSP90 prolongs the retention time for ${ }^{131} \mathrm{I}$ in NIS-transfected FRO-19 tumor cells. Treatment with radioiodine in poorly differentiated refractory thyroid cancers is often inadequate due to resistance. These compounds may be a novel mechanism of increasing uptake, a recent focus in PTC research.

The rationale for pursuing HSP90 inhibitors in RET mutant cancer cells is not only its role as an HSP90 client protein (7). The shared lineage of medullary thyroid cancers (MTCs) and neuroendocrine tumors has been well explored (16). The potential of HSP90 inhibitors in NETs and dual treatment with mTOR or AKT inhibitors has been seen $(17,18,19)$.

Here, we show that in two MTC cell lines, oncogenic targets are inhibited together with cell proliferation. Apoptosis was observed following prolonged treatment with these cell lines. In the PTC cell line, we saw similar growth effects and an NIS-independent increase in uptake of radioactive iodine. Advanced cancers have multiple genetic alterations that drive malignant growth. It is established that often once the initial oncogene has been targeted, resistance develops to the treatment through further mutations. The potential benefit of HSP90 inhibition is that in addition to oncogenic RET inhibition, the simultaneous inhibition of kinases within downstream signaling cascades such as ERK and AKT.

\section{Methods}

\section{Cell culture}

TT cells, derived from an MTC with an $\mathrm{RET}^{\mathrm{C} 634 \mathrm{~W}}$ mutation (a frequently occurring mutation in MEN2A syndrome), were obtained from the American Type Culture Collection (Manassas, VA, USA). MZ-CRC-1 cells were derived from a malignant pleural effusion from a patient with metastatic medullary thyroid carcinoma with an $\mathrm{RET}^{\mathrm{M} 918 \mathrm{~T}}$ mutation (a mutation present in $>95 \%$ of cases of MEN2B syndrome). TPC-1 cells harbor the RET-PTC1 rearrangement which consists of a fusion gene between RET and CCDC6. All three cell lines have been genetically fingerprinted by either SNP-CGH or polymorphic short tandem repeat (STR) and verified to be unique $(20,21)$. TT cells were grown in F12 Ham's media supplemented with $10 \%$ fetal bovine serum (FBS, Thermo Fisher Scientific, Waltham, MA, USA). MZ-CRC-1 cells were grown in DMEM supplemented with 10\% FBS. TPC-1 cells were

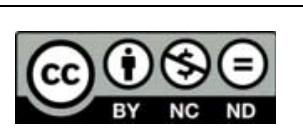
This work is licensed under a Creative Commons
Attribution-NonCommercial-NoDerivatives 4.0 International License. 
grown in DMEM-high glucose media supplemented with 5\% FBS. All media were supplemented with glutamine and 100 units/ml penicillin-streptomycin unless specified.

\section{Drug preparation}

AUY922 (5-(2,4-dihydroxy-5-isopropyl-phenyl)-N-ethyl-4(4(morpholinomethyl)phenyl)isoxazole-3-carboxamide methanesulfonate) is an isoxazole-based compound which competitively inhibits the ATPase activity of HSP90. AUY922 potently inhibits HSP90 with an $\mathrm{IC}_{50}$ of $30 \mathrm{nM}$ as measured in a fluorescence polarization assay (22). Powder was stored at $-20^{\circ} \mathrm{C}$ in a light sensitive container. Aliquots of $10 \mu \mathrm{l}$ with $10 \mathrm{mM}$ stock concentration were stored at $-20{ }^{\circ} \mathrm{C}$ to avoid multiple freeze-thaw repetitions. The HSP90 inhibitor AUY922 was kindly provided under a material transfer agreement with Novartis Institutes for Biomedical Research (Basel, Switzerland).

\section{Cell cycle}

Cell cycle analysis was performed using propidium iodide (PI) (Merck KGaA, Darmstadt, Germany). Cells were plated in triplicate in six-well plates at 1 million cells per well. The following day, cells were treated with increasing concentrations of AUY922. Cells were exposed to the compound for $72 \mathrm{~h}$. Cells were washed twice in PBS, spun at $300 \boldsymbol{g}$ for $2 \mathrm{~min}$ and vortexed between each wash. Cells were resuspended in $700 \mu$ of PBS. Each sample was treated with a master mix containing $50 \mu \mathrm{l}$ RNAse A (20 mg/ml, Merck), $200 \mu \mathrm{l} \%$ Triton X-100 (Merck), and $200 \mu 110 \mathrm{mg}$ PI. Cells were incubated at $4{ }^{\circ} \mathrm{C}$ for $30 \mathrm{~min}$ and then analyzed on the FACS Calibur flow cytometer (Becton Dickinson, Franklin Lakes, NJ, USA). Cell cycle distribution (G0/G1, S, G2/M) analysis was subsequently performed using Modfit LT software (Verity Software House, Topsham, ME, USA) to model mathematically the DNA histogram and thus objectively determine the percentage of cells in each phase.

\section{Cell proliferation assay}

The CellTitre 96 Aqueous One Solution Cell Proliferation Assay kit was utilized as per the manufacturer's instructions (Promega, Fitchburg, WI, USA). Cells were plated in triplicate in a 96-well plate at 30\% confluence. The following day, cells were treated with different concentrations of AUY922. The next day, $20 \mu \mathrm{l}$ of a solution containing 3-(4,5-dimethylthiazol-2-yl)-5-(3-carboxymethoxyphenyl)-2-(4-sulfophenyl)-2H-tetrazolium (MTS) was added and cells were incubated for $3 \mathrm{~h}$ at $37^{\circ} \mathrm{C}$. This experiment was repeated at four time points $(24,48,72$, and $96 \mathrm{~h}$ ) to determine the greatest inhibitory effect of the drug. The Sunrise Tecan microplate reader (Tecan Group, Mannedorf, Switzerland) was used to read the plate at $490 \mathrm{~nm}$. Absorbance data was imported into GraphPad Prism where the half maximal inhibitory concentration $\mathrm{IC}_{50}$ was determined by GraphPad software analysis version 6.0 (GraphPad Software, San Diego, CA, USA).

\section{Apoptosis assessment}

Cell viability was assessed using the mitochondrial membrane dye DilC(5), PI with FACS analysis (23). DilC(5) (1,1-dimethyl-3,3,3'3,3'-tetramethylindodicarbocyanine iodide, $10 \mathrm{mg} / \mathrm{ml}$ Biotium, Inc., Hayward, CA, USA) is a cationic cyanine dye which accumulates in response to membrane potential. The dye accumulates in mitochondria with active membrane potentials, determined as 'live' cells. PI is membrane impermeant and is excluded from live cells.

TT and MZ-CRC- 1 cells were plated on day 0 at 30\% cell confluency in a 12-well plate. The following day cells were washed with PBS and treated with increasing concentrations of AUY922. Cells were kept in an incubator at $37^{\circ} \mathrm{C}$ for 6 days whereupon they were prepared for flow analysis.

Media was removed and cells were washed once with PBS. All media and PBS were transferred to previously labeled flow tubes. Citric saline $(100 \mu \mathrm{l})$ was added to each well for $10 \mathrm{~min}$. Cells were resuspended in PBS and transferred to the same flow tube. Tubes were spun at $300 \boldsymbol{g}$ for $5 \mathrm{~min}$, and excess PBS was removed. Two microlitres of $2 \mu \mathrm{M}$ DiLC(5) was added to each tube. Cells were vortexed and incubated for $20 \mathrm{~min}$ in darkness; then $2 \mu \mathrm{l}$ of PI (10 mg/ml; Merck) was added and incubated for $2 \mathrm{~min}$. DilC(5) was excited by laser at $633 \mathrm{~nm}$ and detected on the FL4 channel. PI was excited by laser at $488 \mathrm{~nm}$ and detected on the FL-2 or FL-3 channel. Cells were analyzed with FACS Calibur flow cytometer (Becton Dickinson) and results analyzed by Cell Quest Pro (BD Biosciences, Franklin Lakes, NJ, USA). By determining that the flow cytometer had a constant flow rate throughout each period of data acquisition and fixing the acquisition time to $20 \mathrm{~s} /$ sample, it was possible to quantify the number of cells. Experiments were done in triplicate and results were normalized to the vehicle treated cells in each experiment. All results are expressed as a percentage relative to vehicle treated cells. For each experiment, live cells (DilC(5) positive, PI negative) were gated as R2. Likewise, necrotic cells (DilC(5) negative, PI positive cells) were gated at R3. 


\section{Radioiodine uptake experiment}

TPC-1 cells were plated in triplicate at 25000 cells/well in a 12-well plate. Two separate plates (also in triplicate) were prepared. The first for addition of perchlorate $\left(\mathrm{KClO}_{4}\right)$ (Sigma) and the second for cell counting (after identical treatments) to adjust the gamma count to the amount of cells to avoid inflation of the data. The following day, the cells were treated with indicated concentrations of the drug. Cells were incubated for $24 \mathrm{~h}$ with treatment at $37^{\circ} \mathrm{C}$. Next, $\mathrm{Na}^{125} \mathrm{I}$ (Iodine-125 radionuclide in $0.1 \mathrm{M}$ $\mathrm{NaCl}$, PerkinElmer, Waltham, MA, USA) was administered to cells. Concentration was determined from stock concentration $4 \mathrm{MBq} / \mu \mathrm{l}$ (original activity). Original activity was determined through online radioactive decay calculator (http://www.radprocalculator.com/ Decay.aspx). Cells were washed once with warm Hanks buffer solution (Invitrogen). Cells were then incubated with $500 \mu \mathrm{l} \mathrm{Na}{ }^{125} \mathrm{I}$ mix at $37^{\circ} \mathrm{C}$ for $1 \mathrm{~h}$. The alternative plate was then treated with $\mathrm{KClO}_{4}$. Perchlorate is a competitive inhibitor of the NIS. Cells were then washed twice with $500 \mu$ ice cold Hanks solution. Cells were then solubilized with $500 \mu \mathrm{l} \mathrm{NaOH}$ (Sigma) per well overnight at $4{ }^{\circ} \mathrm{C}$. The following day, $400 \mu \mathrm{l}$ of each solution was aliquoted and counted on the gamma counter (PerkinElmer). The final reading was adjusted to mean cell number in each treatment group.

\section{Results}

\section{The HSP90 inhibitor AUY922 impairs cell growth MTC cell lines}

The effect of AUY922 on growth of RET mutant MTC cell lines was assessed by MTS assay after treatment for 48 and $72 \mathrm{~h}$. AUY922 inhibited the growth of TT and MZ-CRC-1 MTC cells at doses above $25 \mathrm{nM}$ (Fig. 1A). In the MZ-CRC-1 cell line, AUY922 inhibited cell growth by $45.8 \% \pm 1.45$ at $25 \mathrm{nM}(P=0.002)$ and by $56.1 \% \pm 2.79$ at $100 \mathrm{nM}$ treatment $(P<0.001)$. In the TT cell line, AUY922 inhibited cell growth by $64.3 \% \pm 3.15$ at $25 \mathrm{nM}(P<0.001)$, which was not further enhanced at higher concentrations of the drug. $\mathrm{IC}_{50}$ calculations are shown at 48 and $72 \mathrm{~h}$ (Fig. 1B).

\section{Cell cycle analysis of MTC cell lines shows limited effect after treatment with AUY922}

Cells were treated for $72 \mathrm{~h}$ with an empirically high dose of AUY922 (250 nM), then incubated with PI, and analyzed on the FACS Calibur flow cytometer. Modeling of cell

$\begin{array}{lr}\text { http://www.endocrineconnections.org } & \odot 2016 \text { The authors } \\ \text { DOI: } 10.1530 / \text { EC-15-0098 } & \text { Published by Bioscientifica Ltd }\end{array}$

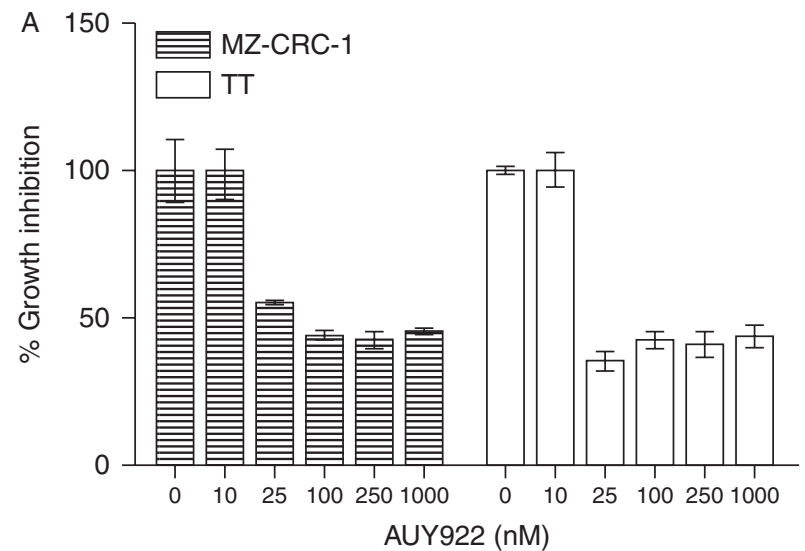

B

\begin{tabular}{|l|c|c|}
\hline & $\begin{array}{c}48 \mathrm{~h} \mathrm{IC}_{50}(\mathrm{nM}) \\
(95 \% \mathrm{C} . \mathrm{I})\end{array}$ & $\begin{array}{c}72 \mathrm{~h} \mathrm{IC}_{50}(\mathrm{nM}) \\
(95 \% \mathrm{C} . \mathrm{l})\end{array}$ \\
\hline TT & $14.30(0.0867-2359)$ & $11.98(0.163-878.2)$ \\
\hline MZ-CRC-1 & $27.27(0.388-1917)$ & $14.3(0.0867-2359)$ \\
\hline
\end{tabular}

Figure 1

Cells were treated for 48 and $72 \mathrm{~h}$ with increasing concentrations of AUY922. After $2 \mathrm{~h}$ of MTS incubation, absorbance was read at $490 \mathrm{~nm}$ Representative experiment performed in triplicate at $72 \mathrm{~h}$. (A) Percent growth inhibition was calculated. Inhibition was statistically significant in both cell lines in concentrations of $25 \mathrm{nM}$ and above $(P<0.002)(B)$ IC50 values were calculated on GraphPad Prism version 6 and are expressed in $\mathrm{nM}$.

cycle distribution was performed using ModFit software. There was a significant difference in the proportion of cells in the G0/G1 phase following AUY922 treatment in MZ-CRC-1 cells. Control MZ-CRC-1 cells had $68.5 \%$ of cells in $\mathrm{G} 1$, which increased to $83.8 \%$ in treated cells $(P=0.01)$ (Fig. 2C and D). However in the TT cells, there was no significant difference in the G0/G1 proportion following treatment with AUY922, 87.8\% vehicle vs $92.4 \%$ treated $(P=0.80)$ (Fig. 2A and B). There were no significant differences in the $S$ or $\mathrm{G} 2 / \mathrm{M}$ proportions in any of the cell lines following treatment $(P>0.05$; Fig. $2 \mathrm{E}$ and $\mathrm{F})$. A representative diagram for each cell cycle is shown in Fig. 2A, B, C and D.

\section{AUY922 inhibits signaling through MAPK and mTOR pathways}

The effect of AUY922 on signaling via MAPK and mTOR pathways was examined through protein expression in western blots. TT and MZ-CRC-1 cells were plated at a density of $70 \%$. The following day, cells were treated with increasing concentrations of AUY922 and then harvested for protein $24 \mathrm{~h}$ later. Following treatment with AUY922, 

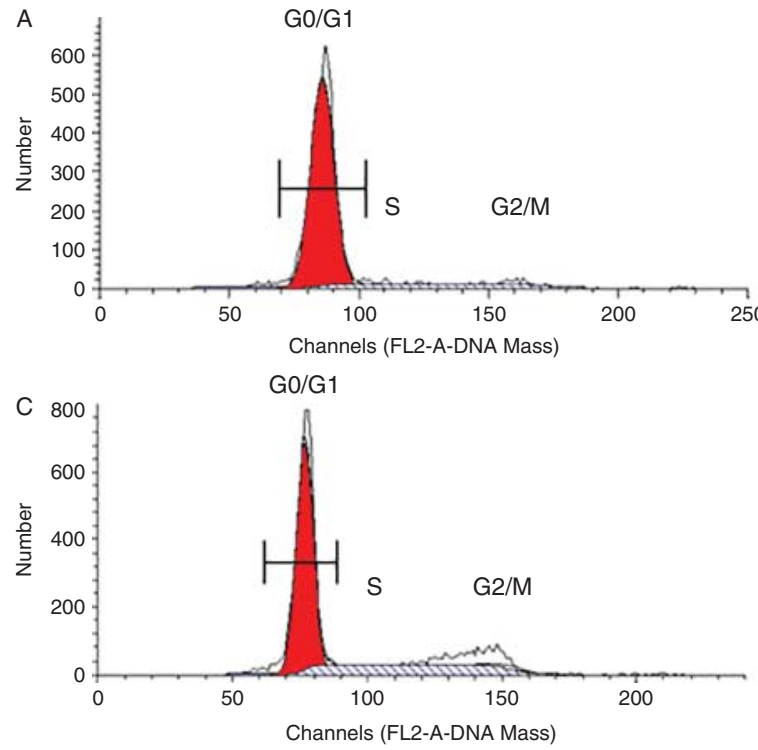

\begin{tabular}{|c|c|c|c|}
\hline TT & G0/G1 & $\mathrm{S}$ & G2/M \\
\hline Vehicle & 87.76 & 12.24 & 0 \\
\hline AUY922 & 92.38 & 7.08 & 0.54 \\
\hline STDev & 13.22 & 3.73 & 2.95 \\
\hline$P$-value & 0.80 & 0.48 & 0.92 \\
\hline
\end{tabular}

Figure 2

Cell cycle analysis of MTC cell lines after AUY922 treatment. (A) TT cells untreated. (B) TT cells treated with $250 \mathrm{nM}$ AUY922. Cells demonstrate no change in cell cycle components following treatment of compound. (C) MZ-CRC-1 cells untreated. (D) MZ-CRC-1 cells treated with $250 \mathrm{nM}$ AUY922 for $72 \mathrm{~h}$. There is an increase in G-1 proportion following

RET signaling was inhibited (Fig. 3). The downstream targets of RET, namely the MAPK and mTOR pathways showed a similar dose-dependent decrease following AUY922 treatment. There was complete ablation of the signal of pS6, pAKT, and pERK at or above 100 nM AUY922 in both cell lines, which corresponded with the strong inhibition of total and pRET at these concentrations. Interestingly, both total ERK and AKT protein (known client proteins of HSP90) were unchanged following AUY922 treatment suggesting that the reduction in pERK and pAKT was due to upstream RET inhibition.

\section{Treatment of MTC cell lines with AUY922 leads to apoptosis}

To explore the effect of AUY922 on apoptosis, TT and MZ-CRC-1 cell lines were treated with increasing doses of AUY922 for 6 days. Following treatment cells were
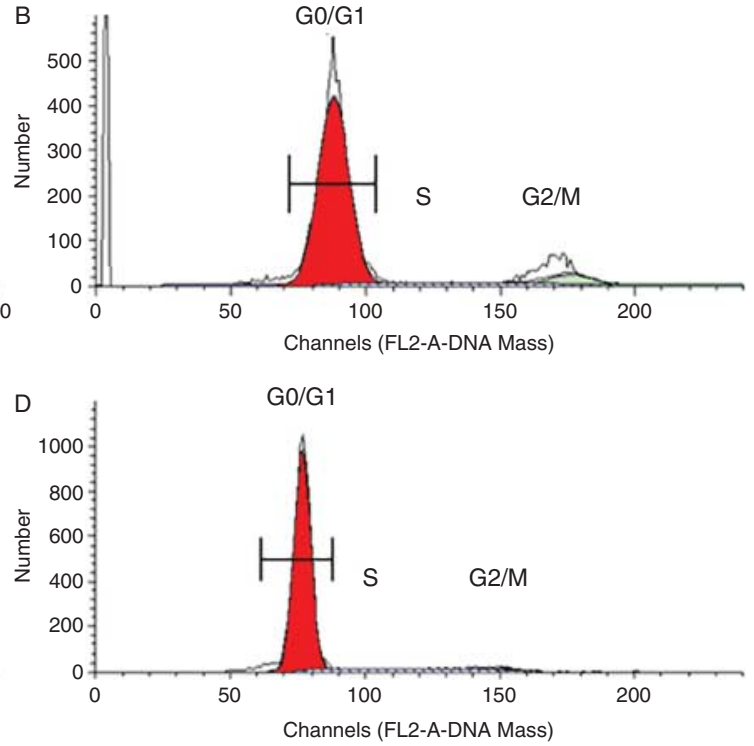

\begin{tabular}{|c|c|c|c|}
\hline MZ-CRC-1 & G0/G1 & S & G2/M \\
\hline Vehicle & 68.49 & 29.62 & 1.89 \\
\hline AUY922 & 90.85 & 8.84 & 0.31 \\
\hline STDev & 11.54 & 9.86 & 7.07 \\
\hline$P$-value & $0.01^{*}$ & 0.21 & 0.33 \\
\hline
\end{tabular}

treatment. Modeling of cell cycle distribution was performed using ModFit LT software. The percentage of cells in each cell-cycle stage are shown for (E) TT and (F) MZ-CRC-1 cells. There was only a significant difference $(* P<0.05)$ in $\mathrm{G} 0 / \mathrm{G} 1$ proportion in $\mathrm{MZ}-\mathrm{CRC}-1$ cells following treatment.

incubated with DilC(5) and PI and analyzed on a flow cytometer. A representative set of experiments is shown for TT cells (Fig. 4A) and MZ-CRC-1 cells (Fig. 4B). Consistently, following treatment there was an increase in apoptosis gated as R3 in Fig. 4A and B. There was a corresponding decrease in live/viable cells, gated as R2 in Fig. $4 \mathrm{~A}$ and $\mathrm{B}$. Figure $4 \mathrm{C}$ and $\mathrm{D}$ shows a dose response of both measures. After treatment with AUY922 at $100 \mathrm{nM}$, live MZ-CRC-1 cells were reduced to $48.6 \% \pm 14.5$ as compared to vehicle treated cells $(P=0.02)$. This was further reduced to $41.3 \% \pm 14.0$ of live cells when $1 \mu \mathrm{M}$ AUY922 was administered $(P=0.018)$. These results were even more potent in the TT cells. Following $50 \mathrm{nM}$ treatment, live cells comprised $24.8 \% \pm 13.9 \%$ as compared with vehicle treated $(P=0.011)$ and reached a plateau at higher concentrations $(21.3 \% \pm 11.7 \%$ as compared with vehicle, $P=0.007$ ) (Fig. 4C and D). 

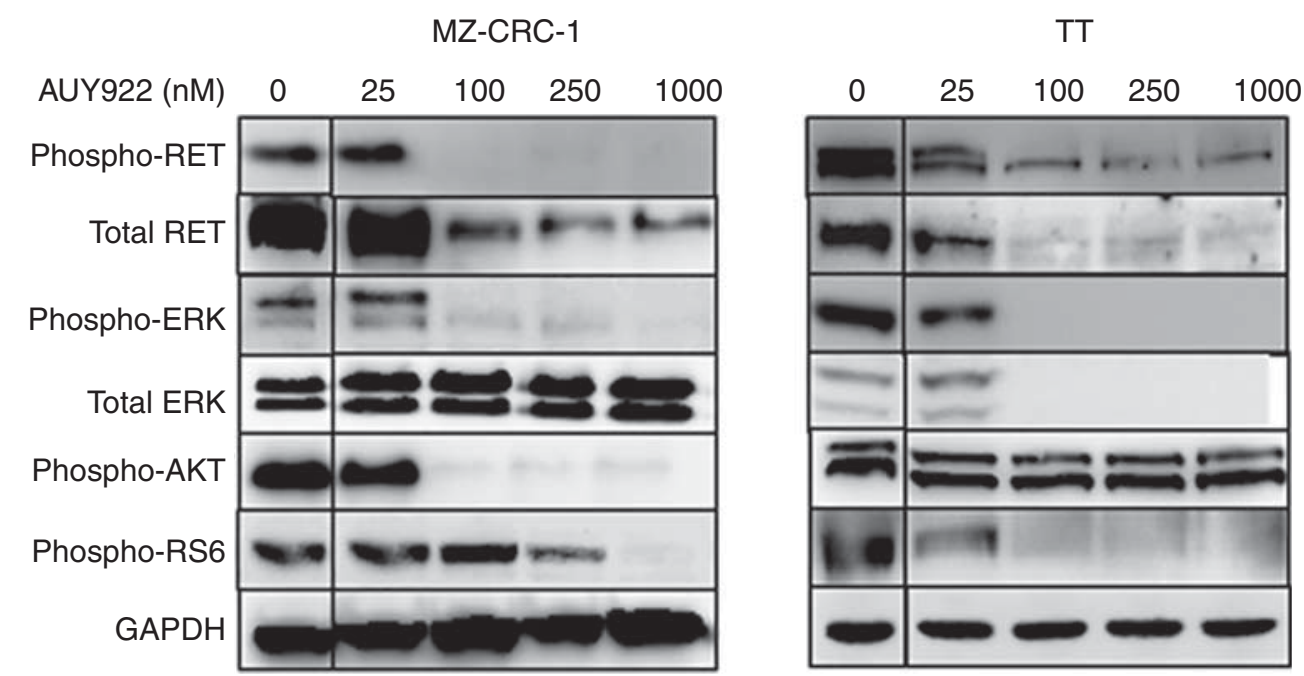

\section{Figure 3}

Protein expression in MTC cell lines following AUY922 treatment. Cells were treated with increasing concentrations of AUY 922 for $24 \mathrm{~h}$. Cells were lysed and prepared for western blotting. Membranes were probed by antibodies, for RET and downstream targets of mTOR and MAPK pathway. Treatment with AUY922 inhibited phosphorylation of RET, ERK, RS6, and AKT in a dose-responsive manner.

\section{AUY922 treatment in RET/PTC1 cell line inhibits RET signaling targets}

Similar analyses were conducted to assess the effects of AUY922 on an RET mutant PTC cell line, TPC-1. Metabolic activity was measured in the MTS assay (Fig. 5A) and showed potent $\mathrm{IC}_{50}$ results $(13.19 \mathrm{nM})$. Inhibition of downstream targets of RET was also observed after being treated with AUY922 for $24 \mathrm{~h}$ (Fig. 5B). There was a marked inhibition of mTOR and MAPK pathways including pERK and pRS6 signal (Fig. 5B). There was some residual pAKT expression detected at $50 \mathrm{nM}$ but it was absent at $100 \mathrm{nM}$ AUY922. In contrast to the MTC cancer cell lines, both total AKT and ERK protein expression was reduced following treatment with AUY922 (Fig. 5B).

\section{Radioiodine uptake is enhanced by AUY922 treatment on the PTC cell line}

TPC-1 cells were treated with increasing concentrations of AUY922 for $24 \mathrm{~h}$. The following day, cells were incubated with ${ }^{125} \mathrm{I}$ for $1 \mathrm{~h}$ with an identical triplicate set further incubated simultaneously with potassium perchlorate $\left(\mathrm{KClO}_{4}\right)$. Following cell lysis the next day, radioactivity was measured on a gamma counter and showed a dose responsive increase following AUY922 treatment. Radioactive iodine uptake increased at $100 \mathrm{nM}$ to $141 \%(1.93 \pm$ 0.14 vs $2.79 \pm 1.23$ c.p.m. normalized to cell number),
$163 \%$ at $250 \mathrm{nM}(1.93 \pm 0.14$ vs $3.22 \pm 1.44)$, and at $1000 \mathrm{nM}$ to $284 \%(1.93 \pm 0.14$ vs $5.85 \pm 1.5)$ as compared to vehicle treated cells. However, only the $1-\mu \mathrm{M}$ cohort was statistically significant $(P=0.015)$ (Fig. 6). The cells treated with $\mathrm{KClO}_{4}$ also demonstrated a statistically significant increase in RAIU following $1 \mu \mathrm{M}$ AUY922 $(P=0.002)$. The treated group without $\mathrm{KClO}_{4}$ was not statistically different from the group which received the competitive inhibitor $(P=0.06)$, consistent with the observed effect of AUY922 on iodine uptake and/or retention being independent of the NIS.

\section{Conclusion}

Targeted therapy focusing on inhibition of single oncogenes has made significant inroads into promising cancer treatments. However, in many reports, despite an initial promising response, these malignancies develop secondary mutations and form resistance to targeted chemotherapy drugs through escape pathways and feedback loops $(24,25)$. The prognosis for patients with radioiodine and chemotherapy resistant metastatic thyroid cancer is extremely poor. Some alternative therapeutic strategies currently being investigated include: re-inducing NIS expression and iodine uptake by treatment with retinoic acid, which also has anti-proliferative and pro-apoptotic effects upon thyroid cancer cells. The utility of PPAR agonists are also being studied for their anti-tumorigenic

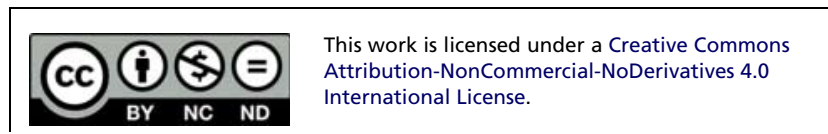



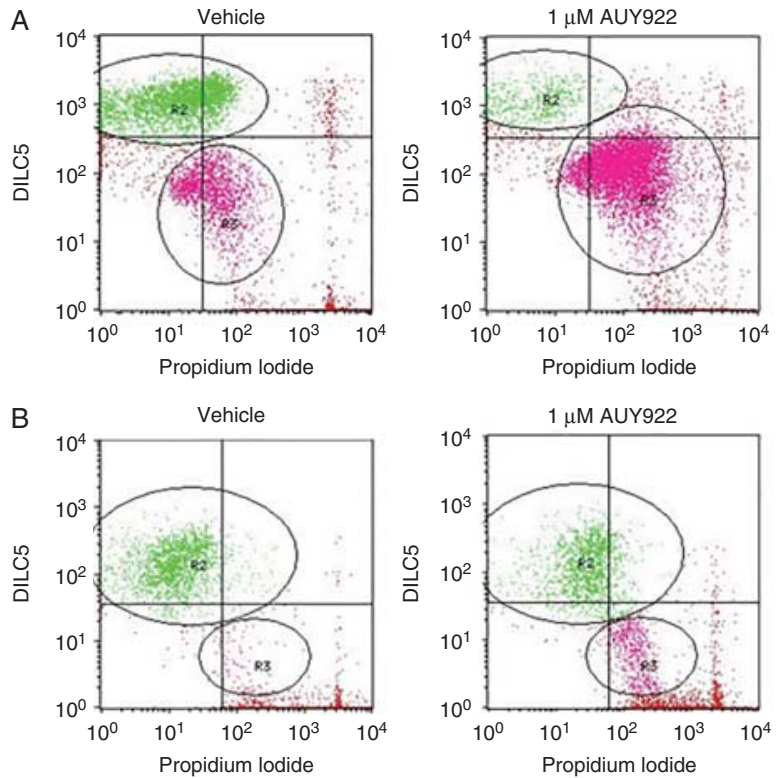

Figure 4

DilC(5) vs PI flow cytometry analysis on MTC cell lines. (A and B) DilC(5) vs PI flow cytometry analysis on MTC cell lines A:TT and B: MZ-CRC-1 show increased apoptosis following AUY922 treatment. Cells were treated with increasing concentrations of AUY922 for 6 days. Cells were stained with DilC(5) and PI and analyzed on a FACS Calibur flow cytometer. Analysis was

effects (reviewed by Fallahi et al. (26)). HSP90 inhibitors represent yet another strategy to inhibit proliferation pathways in these cancer cells. They simultaneously target multiple pro-oncogenic proteins leading to the inhibition of pro-malignant pathways.

AUY922 destabilizes known client proteins of HSP90 including RET, AKT, and components of the MAPK pathway. mTOR itself may also be a client protein of HSP90 (27). In both the PTC and MTC cell lines, there is growth inhibition following AUY922 treatment (Figs 1A and $5 \mathrm{~A}$ ). The $\mathrm{IC}_{50}$ for both MTC cell lines are very similar (Fig 1B) despite differences in the transforming ability of each mutation within the cell line and are broadly consistent with effects on other cancer cell lines $(10,28)$.

\section{Mechanism of loss of cell viability in MTC cell lines}

AUY922 was shown to have significant effects on both signaling and cell death on RET driven thyroid cancer cell lines. In MTC cell lines there was an unambiguous decrease in cell viability (Fig. 1). In the MZ-CRC-1 cell line there was an increase in G1 arrest following treatment with AUY922, while in the TT cell line the cells remained in proportionally the same phase after treatment (Fig. 2). This may be because MZ-CRC-1 harbors the $R E T^{M 918 T}$
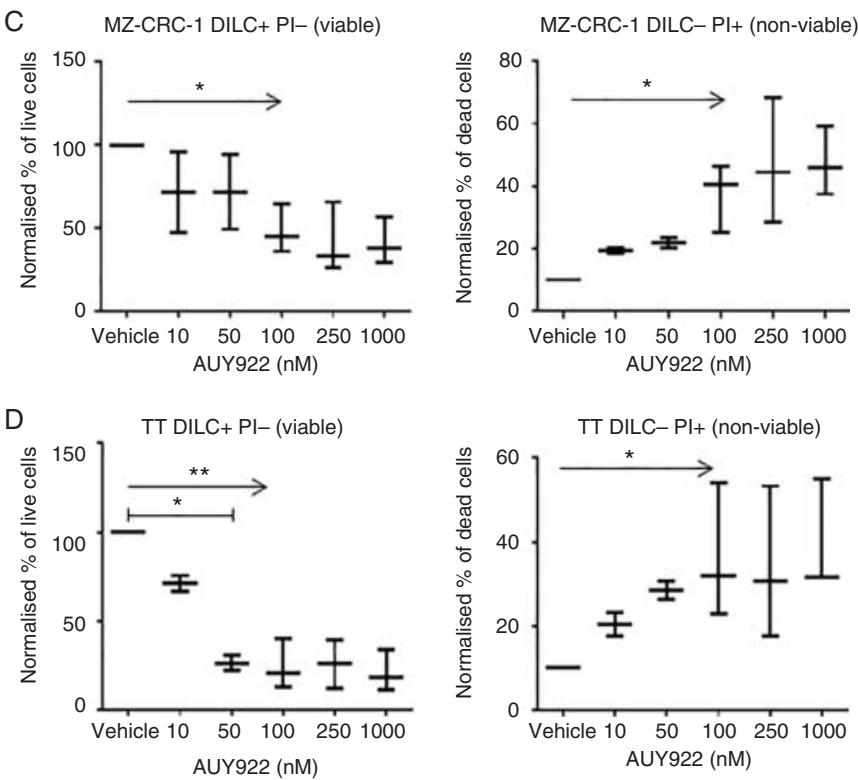

performed by Cell Quest Pro. (A and B) are representative examples of individual experiments which were completed three times. ( $C$ and $D$ ) Combined flow cytometry results for dose response of AUY922. Each individually treated cohort was normalized to vehicle treated cells on that experiment $(* P<0.05, * * P<0.01)$.

mutation and has an enhanced transformative capacity as opposed to the TT cell line, harboring the $R E T^{C 634 W}$ mutation (29). Also, naive TT cells have an extended phase G0/G1 (Fig. 2A). Therefore, there is little capacity for any increase in G0/G1 with treatment, despite a clear reduction in viability (Fig. 1). An extended treatment approach was taken to assess for apoptosis. Cells were treated for 6 days with increasing concentrations of AUY922 and then prepared for analysis of mitochondrial membrane function. There was a decrease in live functioning cells and a corresponding increase in dead cells following treatment (Fig. 4C and D). The precise mechanism through which apoptosis arises following treatment is likely due to inhibition of the pro-survival factors, including AKT (Fig. 3). The MAPK pathway, inhibited here by AUY922, has also been shown to promote cell survival. Hence, the destabilization of RET by AUY922 ensures these pro-survival components are inhibited, and apoptosis ensues.

\section{AUY922 treatment causes inhibition of mTOR and MAPK pathways}

Figure 3 shows inhibition of signaling in the mTOR and MAPK pathways in the MTC cell lines. Similarly in the

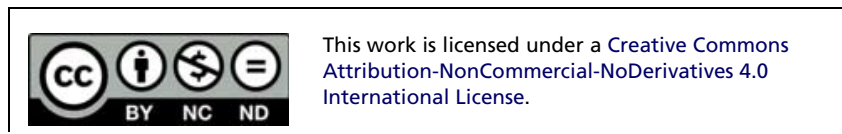




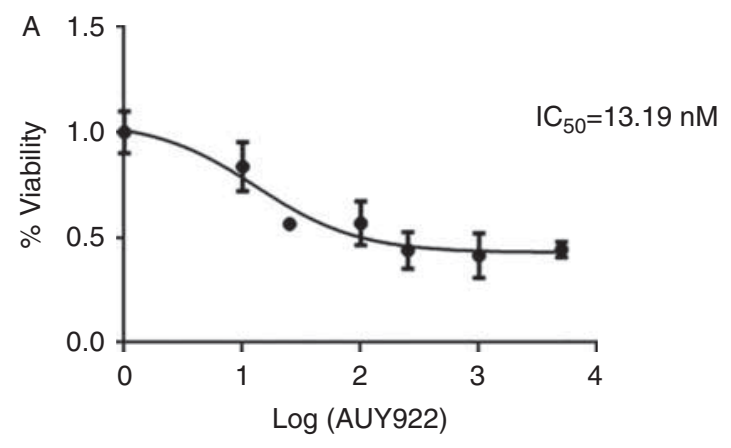

B

\section{Figure 5}

Protein expression and cell viability in the TPC-1 cell line following AUY922 treatment. (A) Cells were treated with increasing concentrations of AUY922 for $24 \mathrm{~h}$. After $2 \mathrm{~h}$ MTS incubation, absorbance was analyzed at $490 \mathrm{~nm}$. Graphs of log (inhibitor) vs response and analysis of nonlinear fit are shown at $24 \mathrm{~h}$. IC50 values were calculated on GraphPad Prism version 6. (B) Cells were treated with increasing concentrations of AUY922 for $24 \mathrm{~h}$. Cells were lysed and prepared for western blotting. Membranes were probed for antibodies to RET and downstream targets of the MTOR and MAPK pathways. Treatment with AUY922 inhibited phosphorylation of RET, ERK, RS6, and AKT in a dose-responsive manner. Furthermore, increasing doses of the AUY922 negatively impacted upon total RET and ERK protein expression.

TPC-1 cell line (Fig. 5B), it is clear that at even lower concentrations of AUY922 there was disruption of these pro-oncogenic pathways. Interestingly, the effect of total ERK protein and total AKT protein following AUY922 administration was different between the MTC and the PTC cell lines. In the PTC cell line, not only was there a clear dose response in the phosphorylated proteins following treatment, but there was also a significant reduction in total protein expression. This result suggests there was an increase in ubiquitination of both ERK and AKT, targeting them for proteasome-mediated degradation (Fig. 5B). This suggests that in the PTC cell line, the HSP90 inhibitor is working effectively on its known client proteins ERK and AKT directly (27). However in the MTC cell lines, inhibition of the proliferative pathway MAPK and the pro-survival pathway AKT was due to inhibition of an upstream target as the total proteins remained stable. Destabilization of RET in the MTC cell lines showed RET to be the architect of the downstream inhibition. Furthermore, it is clear that RET itself was destabilized by this treatment in all cell lines (Figs 3 and $5 \mathrm{~B})$. The difference between the effects seen in the PTC vs MTC cell lines may be due to the slower growth of the MTC cell lines. This may be due to the inherent differences in the cancer genetics of the cell lines, specifically the cellular effects of RET point mutations vs RET/PTC chromosomal rearrangements. However, regardless of mutation type, total RET is clearly destabilized in all cell lines (Figs 3 and 5B) and the signaling activity of downstream mediators of oncogenic RET significantly abrogated.

\section{Radioiodine uptake is enhanced with AUY922 treatment}

Following thyroidectomy, patients with PTC receive radioiodine ablation therapy to eliminate any residual thyroid tissue. Aggressive malignancies, most often mutant $B R A F$ positive, have a reduced iodine avidity rendering this treatment less effective. Due to their poor

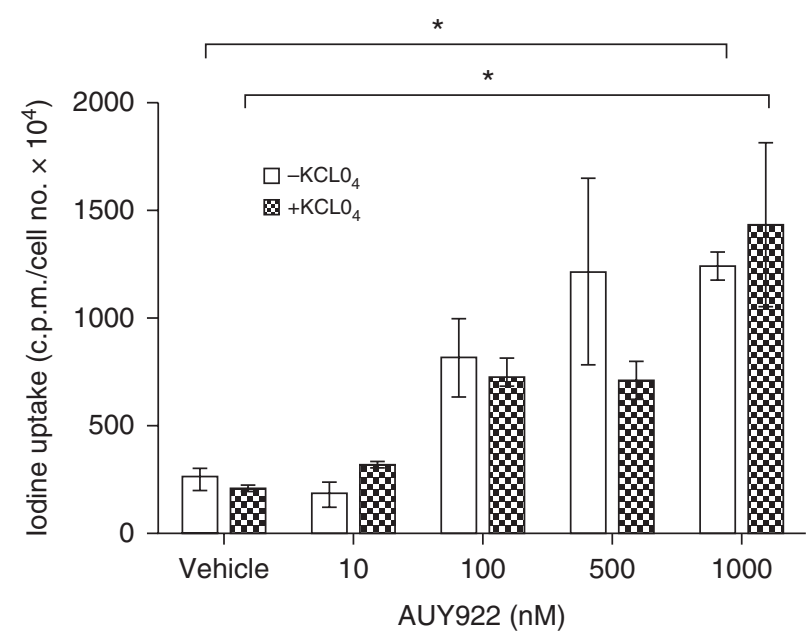

Figure 6

Radioiodine uptake is increased in TPC-1 cell lines following AUY922 administration. Cells were plated to $70 \%$ confluence and then treated with increasing concentrations of AUY922 in triplicate. The following day cells were incubated with $\mathrm{Na}^{125} \mathrm{I}$ or $\mathrm{Na}^{125} \mathrm{I}$ and $\mathrm{KClO}_{4}$ at $37^{\circ} \mathrm{C}$ for $1 \mathrm{~h}$. Cells were washed with $1 \times$ Hanks Buffer and solubilized with $\mathrm{NaOH}$ overnight at $4{ }^{\circ} \mathrm{C}$. The following day cells were counted on gamma counter. There is significant increase in uptake at $1 \mu \mathrm{M}$ AUY922 in both conditions $\left({ }^{*} P<0.05\right)$. 
outcome, and the success of the tyrosine kinase inhibitors (TKIs), the pairing of TKIs with enhanced iodine avidity has been investigated $(30,31)$. This paper presents data showing a dose-dependent increase in the uptake of radioiodine in the TPC- 1 cell line following treatment with AUY922 (Fig. 6). To our knowledge, this is the first time radioiodine avidity has been increased with an HSP90 inhibitor in a PTC cell line. If these results were recapitulated clinically, patients may be able to ensure extended progression-free survival, with enhanced radioiodine ablation of tissue. However, the inability of perchlorate treatment to inhibit the AUY922-stimulated iodine uptake was an unexpected result. As perchlorate functions as a competitive inhibitor of NIS, the similar dose-dependent increase in perchlorate vs non-perchlorate treatment groups suggests an NIS-independent mechanism of increased iodine uptake. Interestingly, Marsee et al. (14) show treatment of 17-AAG of an RET/PTC1 expressing rat thyroid cell line increases radioiodine uptake specifically through the mechanism of decreased iodide efflux. However in contrast to our results, they demonstrated no effect upon iodine uptake by TPC-1 cell line. This further highlights the importance of translating these results into AUY922 clinical trials, as the only clinical trial of HSP90 inhibitors at the time of publication is using 17-AAG. However, clinical use of 17-AAG has been complicated by the compound's poor aqueous solubility and adverse effects such as coupled hepatotoxicity. A recent Phase I clinical trial of AUY922 suggests this drug may be more tolerable than its competitor (32). AUY922 is also currently in clinical trials of non small cell lung cancer. If tolerable, it may be able to be streamlined into clinical trials of thyroid cancer. The results show a potential therapeutic role for this compound in targeted treatment of thyroid cancers.

\section{Declaration of interest}

The authors declare that there is no conflict of interest that could be perceived as prejudicing the impartiality of the research reported.

\section{Funding}

M L Gild was awarded the Australian Postgraduate Award. M Bullock and R J Clifton-Bligh were supported by an NHMRC project grant (1061941).

\section{References}

1 Li Y, Zhang T, Schwartz SJ \& Sun D. New developments in Hsp90 inhibitors as anti-cancer therapeutics: mechanisms, clinical perspective and more potential. Drug Resistance Updates 200912 17-27. (doi:10.1016/j.drup.2008.12.002)
2 Kamal A, Thao L, Sensintaffar J, Zhang L, Boehm MF, Fritz LC \& Burrows FJ. A high-affinity conformation of Hsp90 confers tumour selectivity on Hsp90 inhibitors. Nature 2003425 407-410. (doi:10.1038/nature01913)

3 Park JW, Yeh MW, Wong MG, Lobo M, Hyun WC, Duh QY \& Clark OH. The heat shock protein 90-binding geldanamycin inhibits cancer cell proliferation, down-regulates oncoproteins, and inhibits epidermal growth factor-induced invasion in thyroid cancer cell lines. Journal of Clinical Endocrinology and Metabolism 200388 3346-3353. (doi:10.1210/jc.2002-020340)

4 Richter K, Soroka J, Skalniak L, Leskovar A, Hessling M, Reinstein J \& Buchner J. Conserved conformational changes in the ATPase cycle of human Hsp90. Journal of Biological Chemistry 2008283 17757-17765. (doi:10.1074/jbc.M800540200)

5 Kamal A \& Burrows FJ. Hsp90 inhibitors as selective anticancer drugs. Discovery Medicine 20044 277-280. (doi:10.1097/01.cad.0000136876. 11928.be)

6 Siegelin MD. Inhibition of the mitochondrial Hsp90 chaperone network: a novel, efficient treatment strategy for cancer? Cancer Letters 2013333 133-146. (doi:10.1016/j.canlet.2013.01.045)

7 Alfano L, Guida T, Provitera L, Vecchio G, Billaud M, Santoro M \& Carlomagno F. RET is a heat shock protein 90 (HSP90) client protein and is knocked down upon HSP90 pharmacological block. Journal of Clinical Endocrinology and Metabolism 201095 3552-3557. (doi:10.1210/jc.2009-2315)

8 Eccles SA, Massey A, Raynaud FI, Sharp SY, Box G, Valenti M, Patterson L, de Haven Brandon A, Gowan S, Boxall F et al. NVP-AUY922: a novel heat shock protein 90 inhibitor active against xenograft tumor growth, angiogenesis, and metastasis. Cancer Research 200868 2850-2860. (doi:10.1158/0008-5472.CAN-07-5256)

9 Gandhi N, Wild AT, Chettiar ST, Aziz K, Kato Y, Gajula RP, Williams RD, Cades JA, Annadanam A, Song D et al. Novel Hsp90 inhibitor NVPAUY922 radiosensitizes prostate cancer cells. Cancer Biology \& Therapy 201314 347-356. (doi:10.4161/cbt.23626)

10 Garon EB, Finn RS, Hamidi H, Dering J, Pitts S, Kamranpour N, Desai AJ, Hosmer W, Ide S, Avsar E et al. The HSP90 inhibitor NVP-AUY922 potently inhibits non-small cell lung cancer growth. Molecular Cancer Therapeutics 201312 890-900. (doi:10.1158/1535-7163.MCT-12-0998)

11 Fu W, Sharma SS, Ma L, Chu B, Bui MM, Reed D \& Pledger WJ. Apoptosis of osteosarcoma cultures by the combination of the cyclin-dependent kinase inhibitor SCH727965 and a heat shock protein 90 inhibitor. Cell Death \& Disease 20134 e566. (doi:10.1038/cddis.2013.101)

12 Braga-Basaria M, Hardy E, Gottfried R, Burman KD, Saji M \& Ringel MD. 17-Allylamino-17-demethoxygeldanamycin activity against thyroid cancer cell lines correlates with heat shock protein 90 levels. Journal of Clinical Endocrinology and Metabolism 200489 2982-2988. (doi:10.1210/ jc.2003-031767)

13 Samadi AK, Mukerji R, Shah A, Timmermann BN \& Cohen MS. A novel RET inhibitor with potent efficacy against medullary thyroid cancer in vivo. Surgery 2010148 1228-1236; discussion 1236. (doi:10.1016/j. surg.2010.09.026)

14 Marsee DK, Venkateswaran A, Tao H, Vadysirisack D, Zhang Z, Vandre DD \& Jhiang SM. Inhibition of heat shock protein 90, a novel RET/PTC1-associated protein, increases radioiodide accumulation in thyroid cells. Journal of Biological Chemistry $200427943990-43997$. (doi:10.1074/jbc.M407503200)

15 Elisei R, Vivaldi A, Ciampi R, Faviana P, Basolo F, Santini F, Traino C, Pacini F \& Pinchera A. Treatment with drugs able to reduce iodine efflux significantly increases the intracellular retention time in thyroid cancer cells stably transfected with sodium iodide symporter complementary deoxyribonucleic acid. Journal of Clinical Endocrinology and Metabolism 200691 2389-2395. (doi:10.1210/jc.2005-2480)

16 Gild ML, Landa I, Ryder M, Ghossein RA, Knauf JA \& Fagin JA. Targeting mTOR in RET mutant medullary and differentiated thyroid cancer cells. Endocrine-Related Cancer 201320 659-667. (doi:10.1530/ERC-13-0085)

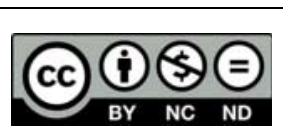

This work is licensed under a Creative Commons Attribution-NonCommercial-NoDerivatives 4.0 International License. 
17 Gloesenkamp C, Nitzsche B, Lim AR, Normant E, Vosburgh E, Schrader M, Ocker M, Scherübl H \& Höpfner M. Heat shock protein 90 is a promising target for effective growth inhibition of gastrointestinal neuroendocrine tumors. International Journal of Oncology $2012 \mathbf{4 0}$ 1659-1667. (doi:10.3892/ijo.2012.1328)

18 Cohen MS, Hussain HB \& Moley JF. Inhibition of medullary thyroid carcinoma cell proliferation and RET phosphorylation by tyrosine kinase inhibitors. Surgery 2002132 960-966; discussion 966-7. (doi:10.1067/msy.2002.128562)

19 Zitzmann K, Ailer G, Vlotides G, Spoettl G, Maurer J, Göke B, Beuschlein F \& Auernhammer CJ. Potent antitumor activity of the novel HSP90 inhibitors AUY922 and HSP990 in neuroendocrine carcinoid cells. International Journal of Oncology 201343 1824-1832. (doi:10.3892/ijo.2013.2130)

20 Schweppe RE, Klopper JP, Korch C, Pugazhenthi U, Benezra M, Knauf JA, Fagin JA, Marlow LA, Copland JA, Smallridge RC et al. Deoxyribonucleic acid profiling analysis of 40 human thyroid cancer cell lines reveals cross-contamination resulting in cell line redundancy and misidentification. Journal of Clinical Endocrinology and Metabolism 200893 4331-4341. (doi:10.1210/jc.2008-1102)

21 Dadon T, Ball D \& Nelkin BD. Misidentification of putative medullary thyroid cancer cell lines RO-H85-1 and RO-D81-1. Journal of Clinical Endocrinology and Metabolism 201398 954-955. (doi:10.1210/ jc. 2012-4181)

22 Nardi L \& Akimov M. Clinical Development AUY922 Investigator's Brochure. 7th Ed. Novartis. 2012.

23 Best OG \& Mulligan SP. Heat shock protein-90 inhibitor, NVP-AUY922, is effective in combination with fludarabine against chronic lymphocytic leukemia cells cultured on CD40L-stromal layer and inhibits their activated/proliferative phenotype. Leukemia \& Lymphoma 201253 2314-2320. (doi:10.3109/10428194.2012.698278)

24 Carracedo A, Ma L, Teruya-Feldstein J, Rojo F, Salmena L, Alimonti A, Egia A, Sasaki AT, Thomas G, Kozma SC et al. Inhibition of mTORC1 leads to MAPK pathway activation through a PI3K-dependent feedback loop in human cancer. Journal of Clinical Investigation $2008 \mathbf{1 1 8}$ 3065-3074.
25 Chapman PB, Hauschild A, Robert C, Haanen JB, Ascierto P, Larkin J, Dummer R, Garbe C, Testori A, Maio M et al. Improved survival with vemurafenib in melanoma with BRAF V600E mutation. New England Journal of Medicine 2011364 2507-2516. (doi:10.1056/ NEJMoa1103782)

26 Fallahi P, Mazzi V, Vita R, Ferrari SM, Materazzi G, Galleri D, Benvenga S, Miccoli P \& Antonelli A. New therapies for dedifferentiated papillary thyroid cancer. International Journal of Molecular Sciences 2015 16 6153-6182. (doi:10.3390/ijms16036153)

27 Basso AD, Solit DB, Chiosis G, Giri B, Tsichlis P \& Rosen N. Akt forms an intracellular complex with heat shock protein 90 (Hsp90) and Cdc37 and is destabilized by inhibitors of Hsp90 function. Journal of Biological Chemistry 2002277 39858-39866. (doi:10.1074/jbc.M206322200)

28 Moser C, Lang SA, Hackl C, Wagner C, Scheiffert E, Schlitt HJ, Geissler EK \& Stoeltzing O. Targeting HSP90 by the novel inhibitor NVP-AUY922 reduces growth and angiogenesis of pancreatic cancer. Anticancer Research 201232 2551-2561.

29 Asai N, Murakami H, Iwashita T \& Takahashi M. A mutation at tyrosine 1062 in MEN2A-Ret and MEN2B-Ret impairs their transforming activity and association with shc adaptor proteins. Journal of Biological Chemistry 1996271 17644-17649. (doi:10.1074/jbc.271.30.17644)

30 Chakravarty D, Santos E, Ryder M, Knauf JA, Liao XH, West BL, Bollag G, Kolesnick R, Thin TH, Rosen N et al. Small-molecule MAPK inhibitors restore radioiodine incorporation in mouse thyroid cancers with conditional BRAF activation. Journal of Clinical Investigation 2011 121 4700-4711. (doi:10.1172/JCI46382)

31 Ho AL, Grewal RK, Leboeuf R, Sherman EJ, Pfister DG, Deandreis D, Pentlow KS, Zanzonico PB, Haque S, Gavane S et al. Selumetinibenhanced radioiodine uptake in advanced thyroid cancer. New England Journal of Medicine 2013368 623-632. (doi:10.1056/NEJMoa1209288)

32 Sessa C, Shapiro GI, Bhalla KN, Britten C, Jacks KS, Mita M, Papadimitrakopoulou V, Pluard T, Samuel TA, Akimov M et al. Firstin-human phase I dose-escalation study of the HSP90 inhibitor AUY922 in patients with advanced solid tumors. Clinical Cancer Research 2013 19 3671-3680. (doi:10.1158/1078-0432.CCR-12-3404) 